\title{
Pemberdayaan Perempuan Melalui Pemanfaatan Limbah Rumah Tangga Menjadi Kerajinan Tangan di Kelurahan Arab Melayu, Kota Jambi
}

\author{
Siti Hodijah $^{1 * *}$, Parmadi $^{2}$, Dwi Hastuti ${ }^{3}$ Heriberta $^{4}$ \\ 1,2,3,4) Fakultas Ekonomi dan Bisnis, Universitas Jambi, Jl. Raya Jambi - Muara Bulian KM. 15, \\ Muaro Jambi, Jambi
}

\begin{tabular}{|l|l|l|l}
\hline Diterima: $15-07-2021$ & Direvisi: 25-07-2021 & Disetujui: 31-07-2021 & Dipublikasi: 18-08-2021
\end{tabular}

\begin{abstract}
The high household activity in the consumption of goods and services is in line with the amount of waste produced. Waste is often an environmental problem that has never been resolved. Types of waste or waste generated by households can be divided into organic and inorganic waste. Organic waste is easy to decompose, while inorganic waste is very difficult to decompose. To overcome the problem of inorganic waste is by recycling them by turning them into handicrafts. This service activity aims to increase the use of household waste in handicrafts. The target group is women. The role of women in the family is significant in maintaining the cleanliness of the environment. Through women's empowerment, it is hoped that inorganic waste in each household can be reduced because it has been processed into various handicrafts.
\end{abstract}

Keywords: women, anorganic waste, handicrafts

\begin{abstract}
Abstrak
Tingginya aktivitas rumah tangga dalam kegiatan konsumsi barang dan jasa sejalan dengan jumlah limbah yang dihasilkan. Limbah seringkali menjadi permasalahan lingkungan yang tidak pernah terselesaikan. Jenis sampah atau limbah yang dihasilkan rumah tangga dapat dibedakan menjadi dua yaitu sampah organik dan anorganik. Sampah organik mudah untuk diuraikan, sedangkan untuk limbah anorganik sangat sulit terurai. Untuk menanggulangi permasalahan sampah anorganik adalah dengan cara daur ulang diantaranya dengan mengubahnya menjadi kerajinan tangan. Kegiatan pengabdian ini bertujuan untuk meningkatkan pemanfaatan limbah rumah tangga menjadi kerajinan tangan. Kelompok sasaran adalah perempuan. Hal ini disebabkan dalam lingkup keluarga peran perempuan sangat penting dalam menjaga kebersihan lingkungan. Melalui pemberdayaan perempuan ini diharapkan sampah anorganik pada masing-masing rumah tangga dapat berkurang, karena telah diolah menjadi berbagai bentuk kerajinan tangan.
\end{abstract}

Kata kunci: perempuan, limbah anorganik, kerajinan tangan

\section{Pendahuluan}

Bertambahnya jumlah penduduk setiap tahunnya membuat aktivitas masyarakat menjadi semakin tinggi. Sisa-sisa dari aktivitas masyarakat ini berupa limbah/sampah rumah tangga yang memberikan dampak yang negatif seperti dampak lingkungan, kesehatan, dan dampak secara social ekonomi jika tidak langsung ditangani dengan baik (Gelbert, dkk. 1996; Suparmini, 2013; Sukesi dkk., 2017). Jika sampah dibiarkan terus menerus akan terjadi

\footnotetext{
*Penulis korespondensi

Email: sitihodijah@unja.ac.id
} 
penumpukan limbah rumah tangga yang akan meninggalkan bau tidak sedap yang akhirnya akan menganggu kenyamanan masyarakat. Oleh karenanya, menurut Tamyiz, dkk. (2018) perlu komitmen bersama dalam pengelolaan sampah.

Pengelolaan sampah dapat dilakukan melalui beberapa tahap diantaranya: 1) Melakukan pemisahan antara sampah organik dan anorganik, 2) Pencacahan dan fermentasi sampah, 3). Pengeringan, 4). Penepungan, 5). Pencampuran dan pembuatan pellet (Bestari, dkk, 2011, dan Widyawati \& Widalestari, 1996). Pengelolaan sampah yang baik akan memberikan dampak positif bagi masyarakat. Sampah anorganik dapat didaur ulang dan menciptakan nilai tambah tersendiri. Sampah organic juga akan memberikan dampak yang positif jika diolah menjadi pupuk. Misalnya sampah dan kotoran sungai di Amerika yang telah dikeringkan sering digunakan sebagai pakan ternak dan mampu meningkatkan produksi susu dan berat badan ternak (Mara \& Caricrss, 1994). Kandungan sampah yang banyak mengandung mineral, nitrogen, kaliunm, vitamin B-12 yang sangat dibuituhkan oleh hewan ternak.

Pengelolaan sampah rumah tangga menjadi kerajinan tangan merupakan salah satu bentuk pengelolaan sampah anorganik. Kerajinan tangan berkaitan dengan kreativitas. Menurut Baron (1969) kreativitas adalah kemampuan untuk menghasilkan atau menciptakan sesuatu yang baru. Selanjutnya menurut Haefele (1962) dalam Munandar (1999) kreatifitas adalah kemampuan untuk mempunyai makna sosial sehingga berdasarkan pendapat tersebut dapat disimpulkan bahwa kreatifitas tidak hanya membuat suatu yang baru tetapi juga bagaimana individu mengkombinasikan sesuatu dari yang sudah ada.

Sejauh ini upaya pemanfaatan limbah anorganik sebagai bahan kerajinan tangan yang ada di masyarakat kurang berkembang dengan baik. Sampah anorganik adalah sampah yang dihasilkan dari bahan-bahan non-hayati, baik dan sulit untuk diuraikan oleh alam (Marliani, 2014). Oleh karenanya kegiatan pengabdian ini bertujuan meningkatkan pemanfaatan limbah rumah tangga menjadi kerajinan tangan di masyarakat. Kegiatan pengabdian ini dilaksanakan di Kelurahan Arab Melayu, Kota Jambi.

Kelompok sasaran kegiatan pengabdian ini adalah para wanita yang berada di Kelurahan Arab Melayu. Pemilihan wanita sebagai sasaran kegiatan karena mereka memiliki lebih banyak waktu dibandingkan dengan laki-laki. Potensi kreativitas yang dimiliki wanita akan juga lebih tinggi di bandingkan dengan laki-laki.

Melalui kegiatan ini juga diharapkan akan terbuka peluang bagi wanita untuk memberikan tambahan pendapatan bagi keluarga. Selain mengurus rumah tangga pembuatan kerajinan tangan bukanlah perkerjaan yang menyita waktu karena pekerjaan ini dapat dikerjakan sewaktu-waktu (Rahim \& Mokoginta, 2017).

\section{Metode}

Kegiatan pengabdian masyarakat di Kelurahan Arab Melayu Kecamatan Pelayangan Kota Jambi dilaksanakan melalui tahapan-tahapan sebagai berikut:

\section{Tahap Perencanaan}

Tahap perencanaan merupakan tahap kegiatan pengabdian kepada masyarakat. Berdasarkan hasil rapat disepakati bahwa tema dan agenda pengabdian kepada masyarakat adalah pembinaan masyarakat di Kelurahan Arab Melayu melalui pemberdayaan perempuan melalui pengelolaan limbah sampah menjadi kerajinan tangan. 


\section{Tahap Pendekatan}

Pada tahap ini, tim pengabdian kepada masyarakat melakukan pertemuan dengan Kepala Kelurahan dan masyarakat yang berada di Kelurahan Arab Melayu untuk menyampaikan draft proposal rencana kegiatan pengabdian kepada masyarakat. Langkah ini dilakukan supaya masyarakat dan aparat kelurahan dapat menentukan tanggal pelaksanaan kegiatan dan mendukung kegiatan ini dapat berjalan dengan lancar.

\section{Tahap Pelaksanaan}

Pelaksanaan kegiatan dilakukan dengan metode ceramah dan praktek. Setelah sesi ceramah dan praktek dilanjutkan dengan sesi diskusi dan tanya jawab.

\section{Tahapan review dan evaluasi}

Pada tahapan ini, tim pengabdian melalukan review dan evaluasi terhadap kegiatan yang telah dilakukan. Aspek-aspek yang direview dan evaluasi terkait dengan capaian kegiatan, kendala yang dihadapi dan solusi perbaikan ke depannya.

\section{Hasil dan Pembahasan}

Sampah menumpuk akan menyebabkan permasalahan bagi masyarakat sekitar jika tidak di tanggulangi dengan cepat. Penyelesaian masalah dapat dilakukan dengan cara memilah sampah menjadi 2 bagian yaitu sampah organik dan sampah anorganik. Untuk sampah organik dapat dijadikan sebagai pupuk atau makanan hewan. Untuk sampah anorganik dapat dijadikan berbagai barang yang bernilai ekonomi bagi masyarakat seperti produk-produk kerajinan tangan.

Dalam kegiatan pengabdian kepada masyarakat di Kelurahan Arab Melayu ini, tim pengabdian memberikan pengetahuan dan keterampilan kepada kelompok sasaran (wanita) mengenai teknik pengolahan limbah anorganik menjadi produk kerajinan tangan. Kegiatan ini dilaksanakan selama dua hari dengan durasi 480 menit.

Selama pelaksanaan kegiatan, peserta telah berhasil dan mampu membuat berbagai jenis kerajinan tangan dari sampah anorganik seperti tas, dompet, tempat tisu dan produkproduk hiasan. Dalam kegiatan ini peserta juga dibekali dengan pengetahuan tentang pengelolaan manajemen untuk usaha berbasis masyarakat.

Di akhir kegiatan dilakukan review dan evaluasi atas pelaksanaan kegiatan. Berdasarkan hasil review dan evaluasi terlihat bahwa seluruh peserta memberikan respon positif terhadap kegiatan ini. Peserta berpendapat bahwa pengetahuan dan keterampilan yang telah diperoleh akan dapat menjadi peluang untuk meningkatkan pendapatan keluarga mereka.

Namun demikian, peserta pesimis terkait dengan permodalan dan pemasaran hasilhasil kerajinan tangan yang akan diproduksi. Hal ini disebabkan rendahnya kemampuan dan sumberdaya peserta baik dalam aspek permodalan maupun dalam memasarkan produk kerajinan tangan yang diproduksi.

Terkait dengan kendala yang dihadapi peserta, hasil diskusi menyepakati beberapa hal:

1. Pembentukan kelompok usaha kerajinan tangan yang berbasis sampah anorganik. Pembentukan kelompok ini selain sebagai ajang diskusi juga untuk menjamin dapat dihasilkannya produk secara lebih banyak dengan mutu yang seragam.

2. Mengembangkan kerjasama dengan lembaga-lembaga lainnya misalnya mini market, koperasi, bank dan pengusaha. 
Membekali kelompok-kelompok usaha kerajinan tangan ini dengan pengetahuan dan keterampilan pemasaran online melalui internet, baik website, media sosial maupun platformplatform lainnya.

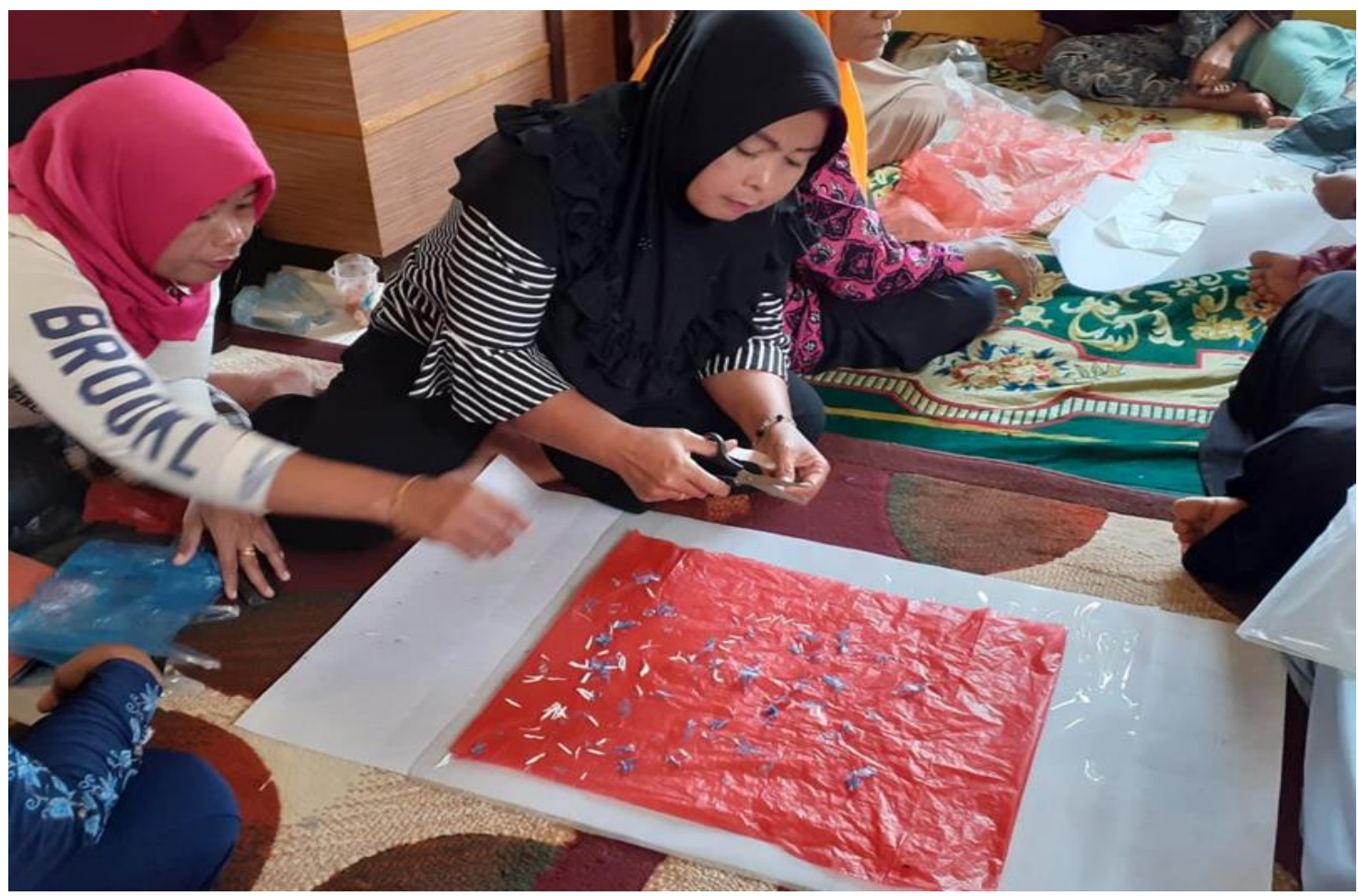

Gambar 1. Pemotongan Plastik sebagai Bahan Dasar Motif Tas

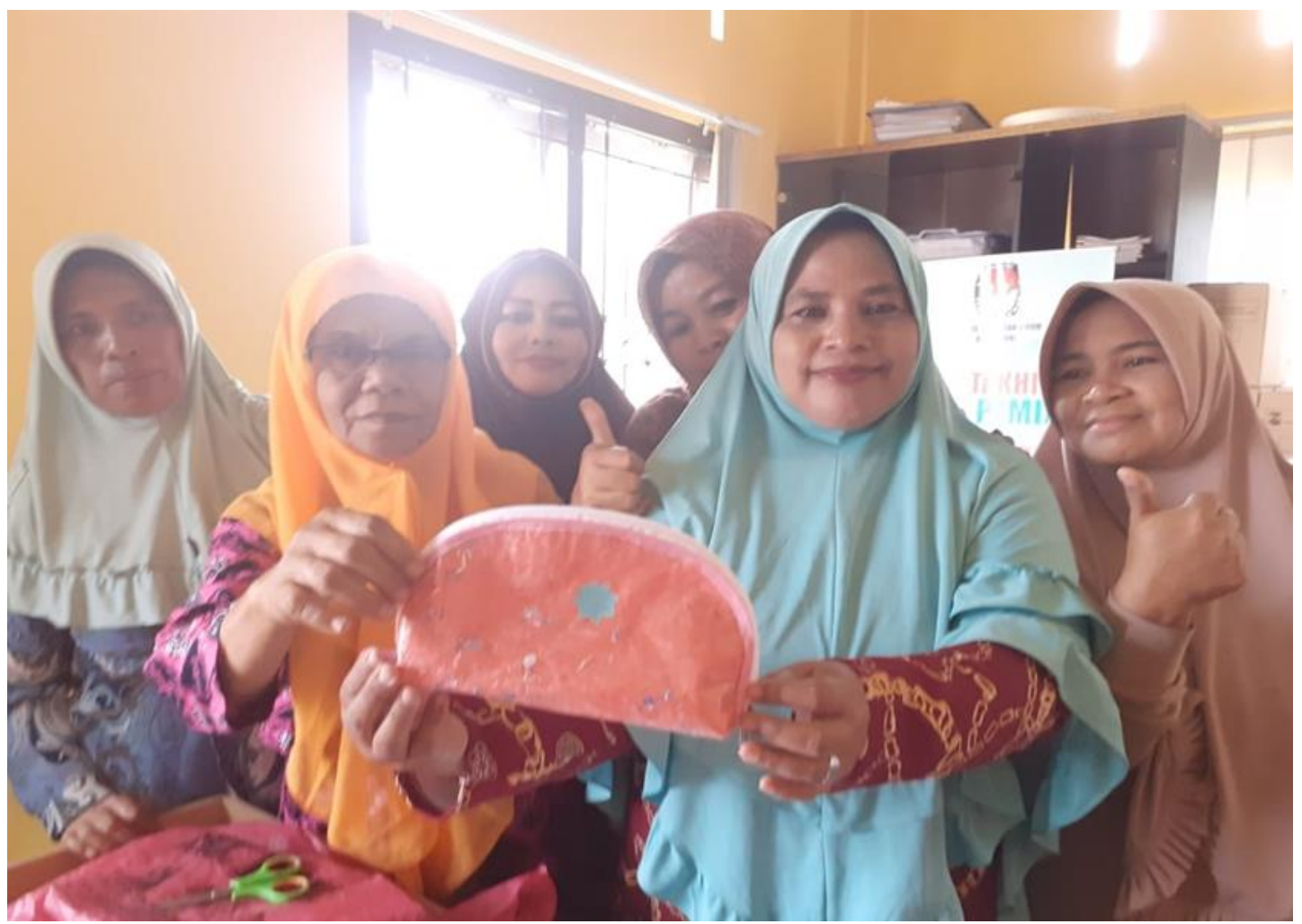

Gambar 2. Produk Tas Olahan Plastik yang Dihasilkan Melalui Pemberdayaan Perempuan 


\section{Kesimpulan dan Saran}

\section{Kesimpulan}

Tingginya aktivitas rumah tangga menyebabkan sampah khususnya sampah anorganik menjadi permasalahan lingkungan yang tidak pernah terselesaikan. Oleh karena itu untuk menanggulangi permasalahan sampah anorganik adalah dengan cara daur ulang, salah satunya dalam bentuk mengubahnya menjadi kerajinan tangan yang memiliki nilai tambah dan nilai jual.

Dalam konteks pemanfaatan sampah menjad produk kerajianan tangan ini, pemberdayaan perempuan menjadi penting. Hal ini disebabkan, dalam lingkup keluarga perempuan merupakan garda utama dalam menjada kebersihan lingkungan. Pemberdayaan perempuan dalam pengolahan sampah menjadi produk kerajinan tangan ini juga memberikan dampak positif lainnya yaitu timbulnya peluang untuk meningkatkan pendapatan keluarga.

\section{Saran}

Untuk menjamin keberlanjutan dari pengolahan kerajinan tangan berbasis sampah anorganik ini, diperlukan sinergitas antara masyarakat dengan dinas/lembaga terkait. Selain itu, agar produk yang dihasilkan dapat dipasarkan secara lebih baik, kegiatan pengabdian ini perlu dilanjutkan dengan pelatihan pemasaran online kepada kelompok-kelompok pengrajin yang telah terbentuk.

\section{Ucapan Terima Kasih}

Penulis mengucapkan terima kasih kepada Universitas Jambi yang dalam hal in telah memberi bantuan pendanaan dan dukungan moral sehingga kegiatan pengabdian pada masyarakat ini dapat terlaksana dengan baik dan lancar.

\section{Daftar Pustaka}

Baron, F. (1969). Creative person and Creative Process. Holt Reiehart \& Wiston Bestari, A.G. (2011). Menggambar busana dengan teknik kering. KTSP Gelbert,M., Prihanto, D., \& Suprihatin, A. (1996). Konsep pendidikan lingkungan hidup dan "wall chart". Buku Panduan Pendidikan Lingkungan Hidup. PPPGT/VEDC

Haefele, J.W. (1962). Creativity and Innovation. Michigan University

Mara, D. \& Cairncross,S. (1994). Pemanfaatan air limbah dan ekskreta. ITB Press. Marliani, N. (2014). Pemanfaatan Limbah Rumah Tangga (Sampah Anorganik) Sebagai Bentuk Implementasi Dari Pendidikan Lingkungan Hidup. Jurnal Formatif, 4(2), 124132

Munandar, U. (1999). Mengembangkan bakat dan kreativitas anak sekolah. Rineka Cipta Rahim S. \& Mokoginta, D. (2017). Pemberdayaan masyarakat melalui pemanfaatan kerajinan tangan dalam mengurangi limbah rumah tangga (Sampah) di Kelurahan Tohupo Kecamatan Bongomeme Kabupaten Gorontalo. KKS Pengabdian Lembaga Penelitian dan Pengabdian Masyarakat Universitas Negeri Gorontalo

Sukesi, T.W., Mulasari, S.A., Sulistyawati, S. \& Tentama, F. (2017). Pemberdayaan Masyarakat dalam Pengelolaan Sampah Rumah Tangga. Proceeding. Universitas Ahmad Dahlan Press

Suparmini, S., Khotimah, N., Sumunar, D.R.S., Sudarsono, A. \& Setyawati, S. (2013). Pelatihan Pengelolaan Sampah Rumah Tangga dengan Metode Komposting di Desa Banyurejo Kecamatan Tempel Kabupaten Sleman. Laporan Kegiatan Pengabdian pada Masyarakat. Universitas Negeri Yogyakarta 
Tamyiz, M., Hamidah, L.N., Widiyanti, A. \& Rahmayanti, A. (2018). Pelatihan Pengelolaan Sampah Rumah Tangga di Desa Kedungsumur Kecamatan Krembung Kabupaten Sidoarjo. Journal Of Science and Sosial Development, 1(1), 16-23

Widyawati, E. \& Widalestari, Y. (1996). Limbah untuk pakan ternak. Trubus Agrisarana

(C) 2021 oleh penulis. Pemegang Lisensi JPM, Indonesia. Artikel ini merupakan artikel akses terbuka yang didistribusikan di bawah syarat dan ketentuan Lisensi Atribusi Creative Commons (CC BY-SA) 